\title{
Correction to: Racial Implicit Associations in Psychiatric Diagnosis, Treatment, and Compliance Expectations
}

\author{
Amalia Londono Tobon ${ }^{1}$ • José M. Flores ${ }^{1}$ - Jerome H. Taylor ${ }^{2}$ • Isaac Johnson ${ }^{1}$ - Angeli Landeros-Weisenberger ${ }^{1}$. \\ Okoduwa Aboiralor $^{1} \cdot$ Victor J. Avila-Quintero ${ }^{1} \cdot$ Michael H. Bloch ${ }^{1}$
}

Published online: 5 April 2021

(C) Academic Psychiatry 2021

\section{Correction to: Acad Psychiatry https://doi.org/10.1007/s40596-020-01370-2}

In the original article there is an error in the labels of Table 1, where some of the titles of the columns were transposed. The corrected version of Table 1 is shown below.

Publisher's Note Springer Nature remains neutral with regard to jurisdictional claims in published maps and institutional affiliations.

The online version of the original article can be found at https://doi.org/ $10.1007 / \mathrm{s} 40596-020-01370-2$

Amalia Londono Tobon amalia.londonotobon@yale.edu

1 Yale University School of Medicine, New Haven, CT, USA

2 Children's Hospital of Philadelphia \& University of Pennsylvania School of Medicine, Philadelphia, PA, USA 


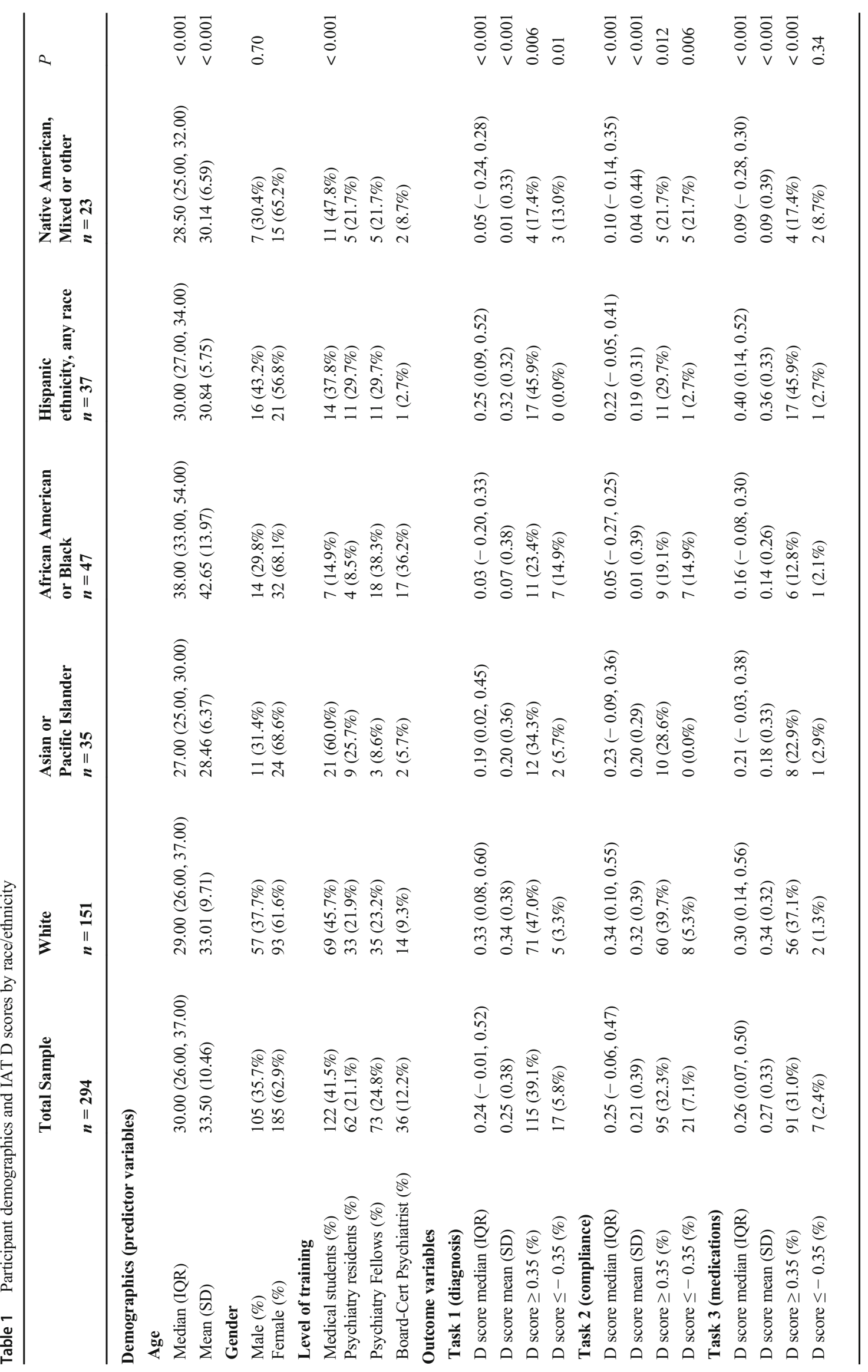

